\title{
LA HISTORIOGRAFÍA ANGLOSAJONA SOBRE LA REVOLUCIÓN RUSA: UNA VISIÓN DEL ÚLTIMO MEDIO SIGLO.
}

\author{
por \\ JORGE SABORIDO \\ Universidad de Buenos Aires - Universidad Nacional de La Pampa
}

El objetivo de este trabajo es el de revisar las principales tendencias de la producción historiográfica elaborada en el mundo anglosajón respecto de un acontecimiento de la trascendencia de la Revolución rusa. Los estudios sobre la misma en el período que estamos abarcando estuvieron atravesados, en el terreno político, por las repercusiones de la Guerra Fría y sus avatares, por el derrumbe del socialismo entre 1989 y 1991; pero además, en el ámbito estrictamente historiográfico, primero por el auge de la historia social y más tarde por el impacto de las concepciones postmodernas. Por otra parte, el abordaje del tema está sin duda relacionado con la visión elaborada por la historiografía soviética, que constituía la contrapartida militante proveniente del mundo socialista.

En líneas generales, y a los efectos de brindar una visión sintética de la cuestión, podemos hacer referencia — siguiendo las líneas interpretativas actuales- a la existencia de dos grandes corrientes historiográficas: la corriente liberal y el «revisionismo» ${ }^{1}$.

Para referirnos a las mismas con elementos de juicio vamos a resumir antes de manera casi telegráfica las líneas fundamentales de la visión soviética del proceso revolucionario.

1 En varios trabajos, Edward Acton, uno de los historiadores que en mayor medida se dedica al tema, ha fundamentado la existencia de una tercera corriente de extrema izquierda, que denomina «libertaria». Uno de los textos en los que desarrolla esta idea es: Acton en Rogovin Frankel, Frankel y Knei-Paz (1992). Sin embargo, creemos que las pautas y elementos que comparten quienes son incluidos en la misma no son suficientemente sólidos como para poder hablar de una alternativa frente a las concepciones que se analizan en este texto.

Hispania, LXIII/3, núm. 215 (2003) 1081-1098 
\# Para los historiadores soviéticos, la Revolución rusa es la mayor prueba de la vigencia de la existencia de leyes generales de la evolución histórica, descubiertas por Marx y desarrolladas por Lenin ${ }^{2}$. Hacia finales del siglo XIX, Rusia puso en marcha un proceso de desarrollo del capitalismo, pero las insolubles contradicciones del régimen y la brutal explotación del capitalismo, agravada por la explotación semifeudal del campesinado, generaron crisis revolucionarias en 1905 y 1917. El proletariado estableció su hegemonía sobre el movimiento de masas que derrocó al zarismo, y los intentos del Gobierno Provisional de consolidar el poder de la burguesía fracasaron rotundamente. A lo largo de 1917, el proletariado, liderado por los bolcheviques, se apartó de su vinculación inicial con los mencheviques, socialistas revolucionarios y movimientos nacionalistas burgueses de las nacionalidades periféricas, y en octubre, aliados con el campesinado pobre, desencadenaron la revolución socialista. Con Lenin a la cabeza, los bolcheviques trabajaron incansablemente para transformar la protesta «espontánea» del proletariado en acción revolucionaria, hasta obtener el éxito. El triunfo de Octubre mostraba la capacidad de Lenin para captar las transformaciones experimentadas por el capitalismo en su fase imperialista, al crear las condiciones para que la revolución se produjera en un país atrasado, en el «eslabón débil» de la cadena imperialista.

Además, para los historiadores soviéticos, la interpretación marxista-leninista de 1917 era confirmada por el conjunto de la historia de la Unión Soviética. Los sucesos revolucionarios de octubre llevaron al poder a la clase trabajadora liderada por el Partido Bolchevique (Partido Comunista a partir de 1918). A pesar de los enormes obstáculos que se presentaron - la destrucción producida por la guerra civil desencadenada por las antiguas clases dominantes apoyadas por los países capitalistas, el aislamiento internacional sufrido en el período de entreguerras, el impacto de la invasión de Hitler y la continua hostilidad de las potencias occidentales - se llevó adelante el proceso de construcción del socialismo. Bajo el liderazgo del partido, la clase trabajadora llevó a cabo esta tarea poniendo en marcha una agricultura colectivizada y desarrollando un programa industrializador que la transformó en una potencia económica. La lucha de clases fue superada, desapareció la desocupación, y el nivel de vida del conjunto de la población mejoró de manera sustancial.

Desde el punto de vista soviético, la propagación de la interpretación marxista-leninista de la revolución estaba estrechamente justamente vinculada con la construcción del socialismo. La Historia constituye una parte vital de la lucha de clases; una adecuada explicación de la revolución va a jugar un papel central en el desarrollo de la conciencia de clase de los trabajadores, en apuntalar la confianza

.2 Los aportes de Lenin pueden sintetizarse en tres puntos: 1) el capitalismo a fines del siglo XIX alcanzó una etapa superior de desarrollo, el imperialismo, caracterizado por la concentración económica, la exportación de capitales y la expansión del dominio capitalista a nivel planetario; 2) en las nuevas condiciones surgidas del imperialismo, la revolución puede estallar no donde éste es mas sólido sino que puede hacerlo «en el eslabón más débil de la cadena imperialista»; 3) el éxito de la revolución depende no sólo de la presencia de factores económicos y sociales «objetivos» sino también de condiciones «subjetivas»: la organización del proletariado en un movimiento revolucionario caracterizado por la conciencia de clase. El papel fundamental en esta situación le correponde al partido revolucionario, un "partido de nuevo tipo», disciplinado y centralizado en su organización, abocado a la concreción de los objetivos revolucionarios.

Hispania, LXIII/3, núm. 215 (2003) 1081-1098 
de las masas en la tarea de edificar el socialismo bajo el liderazgo del partido. Las clases burguesas inevitablemente actuarán para distorsionar la verdad; es entonces tarea del partido, de los historiadores soviéticos, profundizar y divulgar la visión marxista-leninista de la Revolución de Octubre.

En fecha tan temprana como 1920 se creó una comisión especial para relevar el material documental vinculado con la historia del Partido Bolchevique y los eventos de 1917. El acceso a los archivos fue celosamente custodiado y se estableció una rígida censura para bloquear las distorsiones contrarrevolucionarias. Sin embargo, durante la década de 1920 la línea del partido estuvo lejos de ser monolítica: visiones enfrentadas de la revolución formaron parte importante del arsenal utilizado en la lucha por el poder. Con el triunfo de Stalin, en cambio, se estableció un control centralizado sobre las interpretaciones históricas; las voces disidentes fueron acalladas surgiendo una línea única, rígida y sin matices. Esta postura culminó en 1938 con la publicación de la «Historia del Partido Comunista de la Unión Soviética (Bolchevique). Breve curso» ${ }^{3}$.

La visión stalinista le produjo un daño irreparable a la reputación de la historiografía soviética, y sus representantes perdieron toda credibilidad. El nuevo rumbo político adoptado por su sucesor, Nikita Kruschev, a partir de mediados de la década de 1950, modificó esta situación revisando sustancialmente la versión anterior; el acceso a los archivos fue facilitado y se publicó por primera vez una importante masa de nueva documentación ${ }^{4}$. Para poner sólo un ejemplo, la $5^{\circ}$ edición de la Obras Completas de Lenin, publicada entre 1958 y 1965, triplicaba en material la más completa edición de la época stalinista. De cualquier forma, los desafíos a la visión ortodoxa provocaron una fuerte resistencia, y muchos de los cambios iniciados durante la época de Khruschev se hicieron más lentos durante el período dominado por la figura de Leonid Brezhnev. De todas maneras, hasta la irrupción de la perestroika la historiografía soviética no se apartó de las proposiciones básicas de la interpretación marxista-leninista. La legitimación histórica de la Gran Revolución de Octubre, y la línea directa existente entre la victoria bolchevique y el Comité Central del PCUS del momento permaneció como una constante: era como el establishment se veía y aspiraba a ser visto.

Una vez perfilada la corriente historiográfica de origen soviético, pasemos a centrar el tema en las visiones alternativas elaboradas en el ámbito académico anglosajón.

\section{LA EXPLICACIÓN LIBERAL}

Las interpretaciones de carácter liberal, de origen fundamentalmente anglosajón, rechazan de manera frontal las posturas provenientes de la visión so-

3 History (1975).

4 Uno de los acontecimientos más significativos fue la controversia generada por los trabajos de Eduard Burdzhalov, quien cuestionó desde órganos oficiales las tácticas de los bolcheviques durante el período transcurrido entre la revolución de febrero y la llegada de Lenin a Petrogrado en abril. La obra de Burdzhalov más conocida en occidente es Burdzhalov (1987).

Hispania, LXIII/3, núm. 215 (2003) 1081-1098 
viética. Para los historiadores enrolados en la corriente liberal, la historiografía proveniente de la URSS es una distorsión basada no en investigaciones académicas centradas en la búsqueda de la evidencia histórica sino en los requirimientos políticos del régimen surgido de la Revolución de Octubre. Lejos de ser el desenlace inevitable de la intensificación de la lucha de clases en Rusia, ven la revolución como un acontecimiento fortuito, surgido de la coincidencia de una guerra catastrófica, la falta de liderazgo del zar y la ineptitud de los grupos políticos liberales en un escenario político que recién babía iniciado su tránsito hacia una democracia del tipo occidental. Los reclamos de los bolcheviques de representar los verdaderos intereses de las masas son rechazados como una arrogante postura surgida de una doctrina fundamentalmente falsa, y lejos de ver el triunfo del partido en Octubre como la expresión de los deseos de las masas rusas, lo ven como el producto del aprovechamiento de una situación de crisis por parte de una elite de fanáticos revolucionarios.

Frente al papel decisivo que los marxistas atribuían a la lucha de clases, los historiadores liberales enfatizaron la existencia de otras divisiones de importancia, como las divisiones nacionales, que en mayor medida permiten entender la coyuntura revolucionaria.

Su insistencia en la complejidad e indeterminación de la historia los llevó a poner en primer plano la importancia de los procesos políticos. Los historiadores liberales parten de la idea de que la noción de clase no brinda una explicación satisfactoria de las políticas desarrolladas por el Estado y los partidos de oposición; más que explicar la lucha política como una expresión de los conflictos de clase, la tradición liberal le atribuye a los actores una importante capacidad de acción autónoma. Esta significación de la actuación de los «grandes hombres» aparece, por ejemplo, en uno de los historiadores británicos más dedicados al estudio de la Revolución desde la perspectiva que estamos analizando, Leonard Schapiro: su objetivo es «to look at the principal characters concerned as human beings, not as exponents of this of that theory, or as representatives of this or that class interest. I have tried, without, I hope, ignoring economic and social factors, no to let them obliterate what is after all the key to an historical situation - the men who thought or acted in this way or that ${ }^{5}$. Los actores políticos no pueden entonces ser reducidos a marionetas que actúan respondiendo a influencias que les vienen desde abajo. Si bien no se descartan los aspectos económicos, sociales, culturas e ideológicos, otorgan decisiva importancia a las personalidades en su individualidad, forjadas por circunstancias que se vinculan con su historia personal.

El corolario de este énfasis en la crucial importancia y autonomía de la acción política es la tendencia a visualizar el papel de las masas como fundamentalmente subordinado ${ }^{6}$. Justamente, se destacaba que en la atrasada y en buena medida

5 SCHAPIRO (1977:VII)

6 Como ejemplos de esta línea de investigación podemos citar: SCHAPIRO (1960), Daniels (1967), UlAM (1969), KEEP (1976).

Hispania, LXIII/3, núm. 215 (2003) 1081-1098 
analfabeta sociedad rusa las clases bajas oscilaban entre la pasividad y la violencia irracional. En este último caso, sus acciones tendían a ser anárquicas y destructivas, el producto combinado de un intenso resentimiento y expectativas desmedidas. Ignorantes, políticamente inmaduros, estos sectores se movilizaban por rumores, propaganda, demagogia, sin objetivos propios. Por lo tanto, en la coyuntura de 1917 las condiciones generales - guerra, inflación galopante, empobrecimiento generalizado- lanzaron a las masas a la acción, pero el momento y el rumbo de su actuación dependió del accionar de quienes supieron controlar políticamente la situación. En pocas palabras, las masas «were caught up in great events over which they had no control $\gg^{7}$. De todas las organizaciones socialistas, los bolcheviques eran los únicos que tenían claro lo que querían hacer:»they were determined to bring all these mass bodies under the control of disciplined nuclei committed to the objectives of their own party» ${ }^{8}$.

La hegemonía occidental de la visión liberal se vinculó durante muchos años con el limitado abanico de fuentes a los que tuvieron acceso los investigadores occidentales. En la misma, la atención se centró exclusivamente en los aspectos políticos e ideológicos de la revolución, antes que en sus dimensiones sociales y económicas. En parte, sin duda, esta orientación se relacionaba con el hecho de que durante la era stalinista los archivos soviéticos eran inaccesibles, y los documentos y memorias publicados en la Unión Soviética eran manifiestamente tendenciosos. Pero hay que decir también que muchas fuentes editadas durante los años 20 no fueron suficientemente tratadas, dada la citada concentración exclusiva en los temas de carácter político. Además, cuando el acceso a las fuentes se incrementó en los años 50 y 60 la tendencia no varió de manera significativa.

Se fue conformando así un consenso académico occidental alrededor de las posturas liberales, que recién comenzó a ser cuestionado en ámbitos muy puntuales durante los años $60^{\circ}$. El mismo, además, definía al régimen surgido de los acontecimientos de octubre de 1917 como «totalitario» ${ }^{10}$. Uno de los más caracterizados defensores de la utilización de este concepto en la versión elaborada en Occidente durante la Guerra Fría, Leonid Schapiro, era también un experto dedicado al estudio de la Revolución rusa ${ }^{11}$.

\section{LA VISIÓN REVISIONISTA}

La emergencia de una escuela «revisionista» en los estudios anglosajones sobre la Revolución rusa fue posible por la disminución de la tensión EsteOeste a partir de fines de la década de 1950. Su cuestionamiento a la visión

7 KEEP (1976:VIII).

8 KEEP (1976:470).

9 Por supuesto, de ese consenso estaban excluidos, en el ámbito académico británico, tanto Edward H. Carr como Isaac Deutscher.

${ }^{10}$ Sobre el concepto de «totalitarismo» y los debates que suscitó, ver Traverso (2001)

11 SCHAPIRO (1960) y (1977). 
liberal fue equivalente al disconformismo que sentían ante a las posiciones soviéticas ${ }^{12}$. Frente al «consenso» occidental respecto de las argumentaciones liberales, fue surgiendo una nueva corriente de investigadores que abordaron los temas de la Revolución rusa desde la perspectiva de la historia social, haciendo uso de métodos cuantitativos. Se fueron creando las condiciones como para que universidades occidentales enviaran estudiosos a consultar las bibliotecas y, en menor medida, los archivos soviéticos.

Tres son las principales direcciones que tomaron los estudios revisionistas:

1) Se comenzó a examinar el proceso revolucionario «desde abajo», penetrando en el mundo de las fábricas, las aldeas y las trincheras ${ }^{13}$. Un amplio rango de fuentes fue utilizado para reconstruir las ideas y objetivos de las masas: desde correspondencia privada y cartas a la prensa hasta las innumerables publicaciones que emergieron tras la revolución de febrero; desde informes oficiales hasta las resoluciones de los soviets de obreros, soldados y campesinos. En la línea de los conocidos estudios de Edward P.Thompson, se publicaron detalladas monografías en las que se muestra como fue la experiencia de la revolución para los miembros de las clases subalternas.

2) Frente a la concepción liberal de que la revolución sólo podía ser entendida a partir del estudio del accionar de los principales actores políticos, los revisionistas se volcaron hacia el estudio del impacto que el accionar de los hombres comunes produjo sobre los acontecimientos políticos. Una de las consecuencias de estos estudios, por ejemplo, fue el de afirmar sin ningún género de dudas que en vísperas de octubre el Partido Bolchevique, lejos de ser una agrupación minoritaria de intelectuales radicales, tal como lo definía la visión liberal, era un partido compuesto mayoritariamente por miembros de la clase trabajadora ${ }^{14}$.

Más que analizar la historia «social» aislada de los procesos políticos, se buscó entonces destacar la interacción existente la experiencia popular y las mentalidades por una parte, y la lucha por el poder por la otra. Se analizaron las aspiraciones de las masas y se las consideró en su propia racionalidad. Las investigaciones se concentraron en las nuevas organizaciones de masas — soviets, comisiones de fábrica, comités de soldados, Guardias Rojos_-, y la forma en la cual las mismas reflejaban justamente las demandas de las clases subalternas. En contraste con la visión liberal tradicional, estos trabajos sugieren que durante la revolución las masas actuaron sobre los líderes políticos tanto como éstos lo hicieron sobre aquéllas. En palabras de Steve Smith, autor de una fundamental obra revisionista, "Red Petrograd: Revolution in the Factories, 1917-1918», los obreros estaban lejos de ser «irrational, poorly educated, and incapable of independent participa(1955).

${ }^{12}$ El pionero en Estados Unidos de esta corriente es Leopold Haimson. Por ejemplo, Haimson

13 RALEIGH (1987), aporta una interesante serie de trabajos centrado en la situación de los trabajadores en Petrogrado y Moscú.

14 Service (1979).

Hispania, LXIII/3, núm. 215 (2003) 1081-1098 
tion in the political process» ${ }^{15}$. A las mismas conclusiones llegaron las investigaciones sobre el papel de los campesinos ${ }^{16}$ : Allan Wildman, autor de un detallado estudio sobre el Ejército Imperial, «los campesinos en armas», concluye el mismo afirmando que no eran simples marionetas en manos de los bolcheviques sino activos agentes con su propia «vision of land and peace, of their definitive social liberation, but above all of their own collective power to attain such results» ${ }^{17}$.

3) La profundización en el estudio de las dimensiones sociales de la revolución ha sido complementada por los trabajos revisionistas en los campos de la economía y la política. Las visiones tradicionales respecto al desarrollo de la economía prerrevolucionaria han sido sometidas a cuidadosas revisiones ${ }^{18}$, las que también se extendieron al estudio del Estado zarista, el gobierno provisional y los principales partidos políticos, desde los kadetes hasta los bolcheviques. Analizados en conjunto, los trabajos de los revisionistas han abierto el camino a una nueva visión en temas como el descontento popular durante el reinado de Nicolás II, el papel de la intelligentsia revolucionaria, las perspectivas de la economía y de las instituciones democráticas de corte occidental, y los procesos desarrollados en el mismo $1917^{19}$.

En resumen: la historiografía revisionista anglosajona produjo una cantidad significativa de estudios sobre diferentes aspectos de la era revolucionaria, desde la historia de diferentes sectores sociales, especialmente la clase obrera, la historia de la revolución en escenarios puntuales, y la historia de partidos y organizaciones políticas en su contexto social ${ }^{20}$. No obstante, una crítica significativa a los estudios revisionistas fue que estos estudios parciales no dieron lugar al surgimiento de respuestas concretas a preguntas cruciales del tipo de: ¿hubo algún rasgo "particular» en la clase obrera rusa, que permite explicar el estallido de la revolución? ¿los sucesos posteriores a 1905 condujeron a que se forjara una conciencia de clase revolucionaria? ${ }^{21}$.

No obstante, el impacto producido por los estudios revisionistas fue muy significativo durante los años 80 . Por una parte, al coincidir parcialmente con la irrupción de la glasnost en la Unión Soviética de Gorbachov, se produjo un acercamiento significativo entre historiadores soviéticos y occidentales, permi-

is SMITH (1983: 288).

16 FIGES (1990).

17 WILDMAN (1987: 403).

18 GATRELl (1986); DaVies (1998).

19 Aunque sus temas de investigación no se centran específicamente en el proceso revolucionario, la obra del polaco Moshe Lewin, profesor en las universidades de Nueva York, Birmingham y Filadelfia, es fundamental en el impulso adquirido por la corriente «revisionista». Una colección de sus artículos se encuentra en Lewin (1985).

20 BONNELL (1983); FITZPATRICK (1982); KOENKER Y ROSENBERG (1989).

21 Este cuestionamiento aparece puntualizado con claridad en un articulo de Steve Smith (2001), justamente uno de los principales historiadores revisionistas.

Hispania, LXIII/3, núm. 215 (2003) 1081-1098 
tiendo la realización de proyectos conjuntos. En esta línea, por ejemplo, se realizó la traducción al ruso de algunas de las obras revisionistas ${ }^{22}$.

Otra de las implicancias de los trabajos elaborados por los investigadores revisionistas fue enfrentarse con los defensores de las tesis liberales sosteniendo, entre otros temas, la existencia de causas profundas de índole socioeconómica, además de políticas; en la caída del zarismo y en el fracaso de los liberales y de los socialistas moderados. Por supuesto, afirmar que la Revolución de Octubre fue el resultado del accionar consciente de las masas constituía un ataque profundo en la línea de flotación de la visión liberal. La respuesta de los defensores de ésta no se hizo esperar, sosteniendo que el objetivo de los revisionistas era, en palabras de Robert Conquest, «restablecer la vieja leyenda bolchevique».

Sin embargo, la corriente revisionista se enfrentaba también con las tesis centrales de la ortodoxia bolchevique. Por una parte, al destacar el accionar de una clase obrera con objetivos claros disminuía sensiblemente el papel central del Partido Bolchevique; por otra cuestionaba seriamente el «genio» político de Lenin.

En relación con este último tema, la primera biografía de Lenin publicada por Robert Service ${ }^{23}$ llamó la atención respecto de una serie de decisiones potencialmente erróneas adoptadas por éste a partir de su retorno a Rusia en abril de 1917: en ese mes, su planteo reclamando la toma del poder por parte de los soviets a través de la movilización de las masas pudo tener como consecuencia la ilegalización del Partido Bolchevique; también la demora en prevenir a los militantes de abstenerse en intentar la toma del poder en julio nuevamente puso en riesgo la supervivencia del Partido; a mediados de septiembre, asimismo, su prematuro llamado a una insurrección pudo haber conducido a una movilización de mencheviques y socialistas revolucionarios en apoyo de $\mathrm{Ke}$ renski, que sin duda hubiera acabado con los bolcheviques. Aunque nadie ha puesto en discusión el papel de Lenin en los sucesos de Octubre, de la investigación de Service no surge precisamente la imagen de un líder infalible.

De cualquier manera, para la mayor parte de la ortodoxia soviética los trabajos de los revisionistas fueron calificados como una variación de las posiciones occidentales antibolcheviques, una versión sofisticada de la «falsificación burguesa».

\section{EL IMPACTO DE LOS SUCESOS DE 1989-91}

El rápido derrumbe de los regímenes de Europa del este tuvo una profunda repercusión en los estudios sobre la revolución rusa; ésta se ha transformado en

\footnotetext{
22 Probablemente la más importante fue la traducción en 1989 de la monografía de Abraham Rabinowitch, The Bolsheviks come to power (1976).

13 R. Service, (1995). Luego publicó una nueva versión, basada en la consulta de los archivos soviéticos abiertos en la década del 90 , que sin embargo no introduce modificaciones de fondo, aunque enfatiza de manera algo exagerada la importancia de determinados aspectos de su vida privada [Service (2001)].
}

Hispania, LXIII/3, núm. 215 (2003) 1081-1098 
«historia» en un nuevo sentido. En primer término, los historiadores han accedido a una nueva y más amplia perspectiva del régimen que nació en Octubre de 1917: ahora se puede apreciar su comienzo, desarrollo y final, y esta visión global es apropiada para especular respecto del significado del proceso en su conjunto. En segundo término, hasta 1989, la existencia del régimen soviético y de la «guerra fría» implicaba que el estudio de la Revolución rusa no podía ser aislado de las presiones políticas coyunturales. Este escenario ya no existe más, lo que no significa que la Revolución haya dejado de ser objeto de controversia política, pero lo cierto es que la nueva realidad brinda a los historiadores un margen más amplio para escoger sus temas de investigación.

El impacto del hundimiento del socialismo sobre el campo historiográfico soviético fue, como no podía ser de otra manera, enormemente perturbador. Dos notables estudios realizados por Richard W. Davies, profesor de la Universidad de Birmingham, han analizado en detalle las vicisitudes de la historia soviética durante la perestroika y durante la era de Yeltsin ${ }^{24}$. Temas como la enseñanza de la historia de la revolución, la apertura de los archivos y el surgimiento una nueva visión del pasado reciente de los rusos, son abordados de forma que aparece claramente perfilado el impresionante impacto que los sucesos de 1989-91 tuvieron sobre el conjunto de la disciplina.

En relación con las aportaciones historiográficas, el hecho más destacado, y sin duda negativo, lo ha constituido la aparición de un nuevo paradigma (nuevo para el ámbito intelectual ruso). En palabras de uno de sus críticos, «su base ideológica la constituye el rechazo de cualquier posible elemento positivo en el marxismo-leninismo, en el concepto de socialismo. En la práctica esto implica presentar la historia del período soviético exclusivamente desde una perspectiva negativa. Han comenzado a crearse nuevos estereotipos: la idealización del período prerrevolucionario, la canonización de Nicolás II, la revalorización de la Iglesia Ortodoxa Rusa, el rechazo frontal de la lucha de clases, del significado de la revolución de Octubre, etc ${ }^{25}$. Sin duda hay excepciones, entre las que podemos destacar a Víctor Danilov y Boris Kolonitskii, algunos de cuyos trabajos incluso fueron traducidos al inglés ${ }^{26}$, pero la visión dominante es fundamentalmente "denunciatoria». En esta línea, muchos historiadores soviéticos experimentaron una «magica transformación», convirtiéndose en demócratas de la noche a la mañana, denunciando entonces a los sucesos de Octubre y a la figura de Lenin como el punto de partida de todos los sufrimientos que experimentó el país desde $1917^{27}$. La caracterización del régimen surgido de la revolución como «totalitario» se impuso mayoritariamente, asimilándolo al fascismo.

24 Davies $(1989,1997)$.

25 KORNEV, 1994, cit. por KOWALSKI, (1997: 9).

26 DANILOV (1988); KOLONITSKII (1993).

27 En este sentido es interesante la figura de Dmitri Volkogonov, general que fue director del Instituto de Historia Militar durante el régimen, transformándose luego en un virulento crítico del 
Por su parte, en el ámbito que nos ocupa - la historiografía anglosajonala caída de los regímenes de Europa del este produjo, como es natural, un vigoroso resurgimiento de la "visión liberal», sintetizada en los dos voluminosos estudios de Richard Pipes, el influyente profesor de Harvard, asesor de Ronald Reagan en cuestiones de Europa oriental: «The Russian Revolution, 1899$1918 »^{28}$ y «Russia under the Bolshevik Regime, 1919-1924» ${ }^{29}$. El núcleo de la interpretación de la Revolución de Octubre de este «esforzado combatiente de la guerra fría", puede resumirse así: fue un "golpe de estado" conducido por una banda de intelectuales fanáticos sin «mandato popular» que se apoderó de los «centros nerviosos» del Estado, engañando a la mayoría de la población. Cuestiona entonces de manera rotunda la concepción de que los bolcheviques tomaron el poder como consecuencia de una explosión popular. Por lo tanto, la idea revisionista de una «revolución desde abajo» es condenada con dureza: "academic monographs intended to establish this view, filled with statistics and for the most part as unreadable as they were irrelevant for the understanding of the subject, and silent on its political and ideological dimensions, poured forth from the pens of these historians and their pupils ${ }^{30}$. La principal aportación de Pipes residía en el despliegue de una elaborada argumentación destinada a reforzar su postura profundamente antibolchevique.

Otra obra de importancia en esa línea es «The Soviet Tragedy. A History of Socialism in Russia, 1917-1991 ${ }^{31}$, de Martin Malia, veterano profesor de la Universidad de Berkeley (California) y del College de France. Su ensayo se apoya en la tesis de que la revolución fue el resultado de la captura por parte de una minoría «iluminada» - los bolcheviques, o mejor dicho un sector de éstos, encabezado por Lenin y Trotsky- de un proceso en el que las aspiraciones de los trabajadores, dirigidas hacia la conformación de un gobierno de los soviets, se recondujo hacia el objetivo utópico de la "construcción del socialismo» a partir de la conformación de un régimen de partido único. Se construyó entonces el «mito» de la revolución proletaria de Octubre, «the myth of the triumph of the alienated and deshumanized masses over all their sufferings and deprivations ${ }^{32}$. Ese poderoso mito fue, en su visión, la plataforma de lanzamiento de la aventura soviética, la cual, en su análisis, no podía tomar otro rumbo que el que tomó, el de una dictadura totalitaria. Una de sus afirmaciones más fuertes es que «the Soviet experiment turned totalitarian not despite its being socialist but because it was socialist ${ }^{33}$.

conjunto del legado revolucionario. Sus obras principales son las biografías de Stalin [Volkogonov (1991)], Lenin [Volkogonov (1996a)] y Trotsky [Volkogonov (1997)].

28 PIPES (1991).

29 PIPES (1994)

30 Cit. por KOWALSKI (1997: 8).

31 MaLia (1994).

32 Malia (1994: 108).

33 Malia (1994: 498).

Hispania, LXIII/3, núm. 215 (2003) 1081-1098 
Una obra colectiva elaborada en esa misma corriente interpretativa, pero sin duda influenciada por las corrientes revisionistas ${ }^{34}$, planteó explícitamente la necesidad de estudiar «the neglected subjects of history of the Russian Revolution $^{35}$, justamente con el objeto de demostrar que hubo numerosos grupos sociales - desde los partidos antibolcheviques hasta los consejos de trabajadores independientes, pasando por la iglesia y las bandas de campesinos- que resistieron la imposición de la dictadura bolchevique.

Pese al clima favorable a la hegemonía de estas concepciones liberales, las aportaciones revisionistas continuaron su labor. Para citar solo un ejemplo de importancia, una obra de Cristopher Read ${ }^{36}$, profesor de la Universidad de Warwick (Inglaterra), aportó una valiosa visión del proceso revolucionario en varios escenarios del imperio, prestando atención a las experiencias «of the ordinary Russian population ${ }^{37}$, incluyendo temas poco atendidos en general como el de la situación de las minorías nacionales. Una de las interesantes hipótesis que maneja Read es que «the tragedy of the revolution lies in the Bolshevik's failure to recognize the real revolution of the time and instead to pursue their own highly structured presuppositions about what the revolution should have been like and what the chief actors should have been doing» ${ }^{38}$

Ciertamente, sin embargo, se puede acusar a los revisionistas de no prestar adecuada atención a la autonomía de la política en determinadas coyunturas; en particular, se ha destacado que no es suficiente destacar la profundidad de la crisis económicosocial de 1917 para explicar el vuelco de los trabajadores hacia posiciones revolucionarias; para que la revolución se produjera existieron partidos políticos - liderados por la intelligentsia - que con sus programas buscaron ganarse el apoyo de las masas. Los bolcheviques, con Lenin a la cabeza, proveyeron entonces un programa atractivo para satisfacer las demandas de trabajadores, campesinos y soldados, basado en la toma del poder por parte de los soviets. El fracaso de otras alternativas condujo a que sectores crecientes de las clase populares se volcaran en apoyo de los bolcheviques porque éstos, situados fuera del aparato de gobierno, les ofrecieron una opción que sintonizaba con sus expectativas.

La culminación de la tarea revisionista en la segunda mitad de los 90 fueron dos obras, que constituyen - en diferentes registros- la alternativa a la visión liberal liderada por Pipes. Una de ellas es la obra del joven profesor de Cambridge, Orlando Figes, «La Revolución rusa (1891-1924). La tragedia de un pueblo", afortunadamente traducida al castellano ${ }^{39}$.

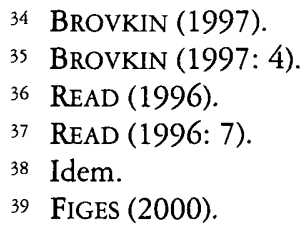


Trabajo de una inusual extensión — casi 1000 páginas - el libro, en palabras de su autor, «es una historia social en el sentido de que se centra sobre todo en la gente corriente. He intentado presentar a las fuerzas sociales más importantes (el campesinado, la clase obrera, los soldados y las minorías nacionales) como los participantes de su propio drama revolucionario en lugar de cómo las 'víctimas' de la Revolución» ${ }^{40}$. Si bien toma distancia respecto de lo que considera el enfoque «finalista» de algunos revisionistas —en este tema asociado, según su visión a las posturas surgidas del mundo historiográfico soviético- recoge las aportaciones del conjunto de éstos para enfatizar que los mismos «han puesto de manifiesto que en lugar de una sola revolución abstracta impuesta por los bolcheviques sobre toda Rusia, a menudo ésta quedó configurada por las pasiones y los intereses locales» ${ }^{41}$.

La otra aportación de envergadura proveniente de los trabajos de los revisionistas es la obra colectiva "Critical Companion to the Russian Revolution", editada por Edward Acton (inglés), Vladimir Iu.Cherniaev (ruso) y William G.Rosenberg ${ }^{42}$ (estadounidense), en la que 46 especialistas - 34 anglosajones, 7 rusos y el resto de diferentes nacionalidades - abordan una gran cantidad de temáticas vinculadas con el proceso revolucionario. En la misma se incluyen una serie de trabajos cuyo elemento común es justamente su carácter crítico, dando cuenta de la complejidad del proceso revolucionario a partir del tratamiento de cuestiones como las de los actores individuales, los partidos políticos, las instituciones, los grupos sociales, las problemáticas nacionales, las cuestiones de género, etc.

En ambas obras, sin embargo, aparece con claridad una nueva situación: que la visión revisionista está atravesada por las transformaciones que produjo sobre la disciplina el cambio intelectual conocido con el nombre de «postmodernismo».

\section{EL IMPACTO DEL POSTMODERNISMO}

Varias fueron las repercusiones de las concepciones postmodernistas sobre los estudios vinculados con la Revolución rusa. Por una parte, algunas de éstas jugaron un papel de importancia en la elaboración de una nueva agenda para la investigación. El énfasis en las cuestiones culturales ${ }^{43}$, en los temas vinculados con el análisis del discurso, han sensibilizado a algunos historiadores respecto de temas antes tratados de manera superficial, impulsándolos a revisar su propio aparato conceptual para reconocer y sacar los presupuestos y cuestiones

\footnotetext{
40 FigES (2000: 16).

41 Idem.

42 ACton, CHerniaev y Rosenberg (1997).

43 Es relación con Rusia, es interesante el tratamiento de la cultura popular en Stites (1992).
} 
implícitas incorporadas al lenguaje que emplean, sean éstas vinculadas con los valores, procesos o relaciones, o acerca del progreso, la modernización o las cuestiones de género ${ }^{44}$. No menos importante es el hecho de que comenzaron a aproximarse a los complejos caminos a través de los cuales los variados discursos de los sujetos que estudian afectaron a la manera como los receptores de esos discursos entendían y actuaban frente al mundo que los rodeaba. En este sentido, el trabajo pionero de Figes y Kolonitskii ${ }^{45}$ sobre el papel que cumplió el lenguaje en conformar las identidades políticas y el discurso político de la Revolución, constituye una interesante aportación para tomar conciencia respecto de las posibilidades que el «giro linguistico» brinda al conocimiento de determinados aspectos del período revolucionario.

Por lo tanto, este tipo de estudios, lamentablemente todavía escasos, han permitido mejorar nuestra comprensión de las relaciones sociales y sus consecuencias políticas mostrando, por ejemplo, los mecanismos a través de los cuales los bolcheviques lograron sintonizar con las aspiraciones de las masas, o también descubriendo el profundo impacto que tuvo la revolución en las relaciones de poder, más allá de las asociadas a las instituciones formales del Estado y a las vinculadas con la propiedad ${ }^{46}$. En algún sentido, entonces, la «nueva historia cultural» constituyó una extensión de la «nueva historia social» que apuntaló la corriente revisionista.

Pero, al mismo tiempo, otros aspectos de la visión postmoderna han contribuido al surgimiento de un clima cultural que favorece la aceptación de las posturas liberales. Esto es así debido a que de un lenguaje supuestamente liberado de sus raíces sociales, se pasó con demasiada facilidad a un terreno en el que se repudiaban los hallazgos mismos del análisis de lo social. Esta postura de escepticismo extremo y crudo relativismo, su rechazo a toda la tradición de investigación cuyas orígenes se encuentran en la Ilustración, si bien no ha conducido al surgimiento de trabajos significativos vinculados con la Revolución rusa, por distintas razones apuntala la postura que defiende el conjunto de la obra de Richard Pipes.

En primer término, como sabemos, este escepticismo ha puesto en entredicho la noción de que existe la posibilidad de una «gran narración» en historia, rechazando la idea de que hay una historia de progreso para contar, sea ésta en términos de ideas o instituciones, de dignidad humana o de hábitos sociales, que puede ser recobrada y explicada. Al cuestionar en general la fe en el poder de la razón, cuestiona entonces la idea de la existencia de la historia como relato racional de las acciones de los hombres. Esta postura se enfrenta directamente con toda aproximación al pasado de corte hegeliano, marxista, e incluso cristiano, pero también, yendo a nuestro tema, ataca las más modestas aspiraciones de las recientes investigaciones respecto, por ejemplo, de las aspiraciones de las masas en el

\footnotetext{
44 Sobre el papel de las mujeres en la revolución, Clements (1997).

45 Figes y KOLONITSKII (2001).

46 Varios de los trabajos de la obra de Acton, Cherniav y Rosenberg abordan esta temática.
} 
último período de la Rusia imperial. Por lo tanto, el efecto general de esta actitud hacia el pasado favorece el abordaje de la Revolución rusa como un acontecimiento dependiente de avatares políticos, del azar, resultando muy poco más que una casualidad que se haya resuelto de la manera en que finalmente ocurrió.

En segundo término, esta corriente escéptica, basada como está en la negación de que el análisis social pueda construir sus propios conceptos, expresa entonces profundas dudas respecto a cualquier abordaje histórico que ponga énfasis en las objetivas condiciones socioeconómicas. Aunque tenga poco que decir respecto de qué puede ser analizado y conocido, su mensaje negativo, su voluntad de rechazar de plano los términos y conceptos de los cuales depende el análisis de lo social, es mucho más crítico con los trabajos de los revisionistas respecto del abordaje liberal, que relega a la periferia los temas económicos y las cuestiones sociales.

En tercer término, como corolario de lo dicho hasta ahora, en la medida en que todos somos prisioneros de un discurso u otro, se tiende no sólo a privilegiar lo subjetivo sino a tratarlo como autónomo. Esto implica que si el estudio del pasado tiene algún sentido, la acción humana y el cambio social deben ser explicados en términos de las ideas, valores e imágenes mentales de la gente. Es esta noción la que ha tenido la más serias implicancias sobre un posible abordaje crítico y reflexivo en relación con el tema de la Revolución rusa, al apuntalar las tradicionales interpretaciones liberales. Es que si aceptamos la primacía causal y la autonomía de las ideas para explicar el desenlace político de la revolución, no hay necesidad de complementar el estudio del mundo mental de los hombres y las mujeres con el análisis de su experiencia material.

\section{A MANERA DE CONCLUSIÓN}

Los estudios anglosajones sobre la Revolución rusa en el último medio siglo se han situado en el corazón de cruciales cuestiones historiográficas y políticas. Como se ha visto, sufrieron primero el impacto de la gran expansión de los estudios de historia social de las décadas de 1960 y 1970, y luego se vieron afectados por las repercusiones de las concepciones postmodernistas. Por otra parte, los avatares de la realidad política de la segunda posguerra - fundamentalmente los avatares de la Guerra Fría - constituyeron un factor condicionante tanto en la elección de los temas como en las características del abordaje, así como el hundimiento de la experiencia socialista introdujo un nuevo factor, sobre todo negativo, en el debate historiográfico.

A la altura de la primera década del siglo XXI, asimilado siquiera parcialmente el impacto de las transformaciones verificadas en los últimos años, cabe entonces formular algunos comentarios:

1) A favor del surgimiento de nuevos temas de investigación existe el hecho objetivo de que se dispone de una gran cantidad de material en condiciones 
de ser analizado; la apertura de archivos, iniciada ya en la época de Gorbachov, ha dado lugar a la aparición de diferentes trabajos ${ }^{47}$. Si bien hay coincidencias respecto a que la nueva documentación difícilmente aporte novedades de significación en aspectos centrales del proceso revolucionario, sin duda va a permitir profundizar en diferentes aspectos del mismo.

2) En relación con esta cuestión, los nuevos temas de estudio introducidos por las concepciones postmodernistas, desde las cuestiones de género hasta el análisis del discurso, pasando por los abordajes de tipo cultural, abren un amplio campo a la investigación.

3) Sin duda, el derrumbe de las experiencias del socialismo real ha contribuido inicialmente a potenciar las posiciones condenatorias, carentes en general de sutileza y crudamente orientadas a descalificar todo lo ocurrido desde 1917 hasta el rápido final. No obstante, considero que la misma cambiante realidad conducirá con rapidez - de hecho esto ya está ocurriendo ${ }^{48}$ - a que se reduzcan al mínimo los abordajes atravesados por los juicios «a priori» para ceder paso a análisis más ponderados, en los que desaparezcan los ecos de la Guerra Fría y se torne posible la elaboración de explicaciones alejadas de la «demonización» a priori de una experiencia en la que creyeron con fuerza millones de personas de varias generaciones.

\section{BIBLIOGRAFÍA}

ACTON, E.(1990): Retbinking the Russian Revolution. Londres, Arnold.

ACTON, E., «The Libertarians vindicated? The libertarian view of the revolution in the ligth of recent Western research». En: Rogovin Frankel, Frankel y Knei-Paz (1992).

Acton, E., V. Iu. Cherniaev, W.G. Rosenberg (Ed.) (1997): Critical Companion to the Russian Revolution. Indianapolis, Indiana University Press.

BONNELL, V. (Ed.) (1983): The Russian Worker. Life and Labor under the Tsarist Regime. Berkeley, University of California Press.

BRovkin, V.(Ed.) (1997): The Bolsheviks in Russian Society. New Haven y Londres, Yale University Press.

BuRDZHAlov, E.N., Russia's Second Revolution. The February 1917 Uprising in Petrograd. Bloomington-Indiana, Indiana University Press.

Clements, B.E. (1997): Bolsbevik Women. Cambridge, Cambridge University Press.

DANIELS, R. (1967): Red October. Nueva York, C.Scribner.

DANILOV, V.(1988): Rural Russia under the New Regime. Londres, Hutchinson.

DAVIES, R.W. (1989): Soviet History in the Gorbachev Revolution. Indianapolis, Indiana University Press

47 Uno de ellos realizado justamente por Pipes, se centró en destacar nuevos aspectos de la personalidad de Lenin a partir de su archivo secreto [Pipes (1998)].

48 La obra colectiva de Acton, Cherniaev y Rosenberg, ya citada, se sitúa claramente en esta línea.

Hispania, LXIII/3, núm. 215 (2003) 1081-1098 
(1997): Soviet History in the Yeltsin era. Londres, MacMillan Press.

FIGES, O. (1990): Peasant Russia, Civil War: The Volga Countryside in Revolution (19171921). Oxford, Oxford University Press.

(2000), La Revolución rusa (1891-1924). La tragedia de un pueblo. Madrid, Edhasa.(Edición inglesa de 1997).

FIGES, O.; B. KOLONITSKII (2001): Interpretar la Revolución Rusa. Valencia, Biblioteca Nueva. (Edición inglesa de 1997).

Gatrell, P. (1986), The Tsarist Economy, 1850-1917. Nueva York, St.Martin's Press. (1994): Government, Industry and Rearmament in Russia, 1900-1914. Cambridge, Cambridge University Pres.

HAIMSON, L.H. (1955): The Russian Marxists and the Origins of Bolshevism. Cambridge, Harvard University Press.

History of the Communist Party of the Soviet Union (Bolsheviks): Short Course (1975), Greenwood, Greenwood Group.

KEEP, J.H.L. (1976): The Russian Revolution: A Study in Mass Mobilisation. Londres, Weidenfeld y Nicholson.

KOENKER, D.; W.G. ROSENBERG (1989): Strikes and Revolution in Russia, 1917. Princeton, Princeton University Press.

KOWALSKI, R. (1997): The Russian Revolution 1917-1921. Londres-Nueva York, Routledge.

LEWIN, M. (1985): The Making of the Soviet System. Nueva York, Methuen.

MALIA, M. (1990): Comprender la Revolución Rusa. Madrid, Rialp.(Edción inglesa de 1980).

Melancon, M. (1990): The Socialist Revolutionaries and the Russian Anti-War Movement 1914-1917. Columbia, Ohio University Press.

PIPES, R. (1991): The Russian Revolution. Nueva York, Vintage.

(1994): Russia under the Bolshevik Regime. Nueva York, Vintage.

(1997): Three «wbys» of the Russian Revolution. Nueva York, Vintage.

(1998): The Unknown Lenin. New Haven-Londres, Yale University Press.

RALEIGH, D.H. (ED.) (1987): The Workers' Revolution in Russia, 1917: the view from below. Cambridge, Cambridge University Press.

READ, C. (1996): From Tsar to Soviets. The Russian people and their revolution, 1917-1921. Londres, UCL Press.

Rogovin Frankel, E.; J.FrANKEL y B. KNEI-PAZ (1992): Revolution in Russia: Reassesments of 1917. Cambridge, Cambridge University Press.

ROSENBERG. W.G. (1974): Liberals in the Russian Revolution: The Constitutional Democratic Party. Princeton, Princeton University Press.

SCHAPIRO, L. (1960): The Communist Party of the Soviet Union. Londres, MacMillan Press. (1977): The Origin of the Communist Autocracy: Political Opposition in the Soviet State, First Phase, 1917-1922. Londres, MacMillan, Press.

SERvice, R. (1979): The Bolshevik Party in Revolution: A Study in Organisational Change, 1917-1922. Londres, MacMillan Press.

(1995): Lenin. Vol.III. The Iron Ring. Londres, MacMillan Press.

Hispania, LXIII/3, núm. 215 (2003) 1081-1098 

2000).

(2001): Lenin. Una biografía. Buenos Aires, Siglo XXI, 2001. Edición inglesa de

SMITH, S. (1983): Red Petrograd: Revolution in the Factories, 1917-1918. Cambridge, Cambridge University Press.

(2001): "Writing the History of the Russian Revolution after the Fall of Communism», en M.Miller, The Russian Revolution. Oxford, Blackwell.

STITES, R. (1992): Russian popular culture. Entertainment and society since 1900. Cambridge, Cambridge University Press.

SunY, R.; A. ADAMS (Eds.): The Russian Revolution and Bolshevik Victory. Visions and Revisions. Lexington-Toronto, Heath, 1990.

TRAVERSO, E. (2001): El totalitarismo. Historia de un debate. Buenos Aires, EUDEBA.

UlAM, A.(1969): Los Bolcheviques. Barcelona, Grijalbo. (Edición inglesa de 1965).

Volkogonov, D. (1991): Stalin. Triumph and Tragedy. Nueva York, Forum.

(1996a): El verdadero Lenin. Barcelona, Anaya y Mario Muchnik. (Edición inglesa de 1992).

(1997): Trotsky. The Eternal Revolutionary. Londres, Harper Collins.

WILDMAN, A. (1980,1987): The End of the Russian Imperial Army. 2 vols. Princeton, Princeton University Press. 